\section{Update of guidelines for surgical endodontics - the position after ten years}

\author{
G. E. Evans, ${ }^{1}$ K. Bishop ${ }^{2}$ and T. Renton ${ }^{3}$
}
IN BRIEF
- Describes the role of the Clinical Standards Committee of the Faculty of Dental Surgery, RCS England in producing a series of clinical guidelines.
- Introduces salient points added to the Guidelines for Surgical Endodontics over the last decade.
- Presents accumulating evidence to support the use of magnification and microsurgical techniques.

This is the first of a series of articles, which will summarise new or updated clinical guidelines produced by the Clinical Standards Committee of the Faculty of Dental Surgery, Royal College of Surgeons of England (FDSRCS). Important developments for the dental profession from a number of clinical guidelines will be presented, commencing with the Guidelines for surgical endodontics. The impact of recent evidence relating to the outcome of surgical endodontics and techniques such as cone beam computed tomography and microsurgical techniques are considered.

\section{INTRODUCTION}

The primary role of the Faculty of Dental Surgery, Royal College of Surgeons of England (FDSRCS) is to enable dentists to achieve and maintain the highest standards of clinical practice and patient care. This is achieved through a variety of activities, one of which is the development and maintenance of a wide range of clinical guidelines. ${ }^{1}$

The guidelines are produced by the Clinical Standards Committee of the faculty and are either the work of the committee itself or the endorsement of work by other bodies such as professional societies, NICE etc.

The committee membership includes representatives from the FDSRCS (Eng) as well as other key stakeholders including professional societies and the Department of Health. The $B D J$ has agreed to publish summaries of any new or updated guidelines developed by the FDSRCS (Eng),

\footnotetext{
Specialist in Endodontics and Part-time Clinical Lecturer in Endodontics, UCL Eastman Dental Institute, 256 Gray's Inn Road, London, WC1X 8LD; ${ }^{2 *}$ Chair Clinical Standards Committee Faculty of Dental Surgery, RCS (England), Consultant in Restorative Dentistry, Specialist in Endodontics ABMU LHB, Morriston Hospital, Swansea SA6 6NL; ${ }^{3}$ Chair Academic Lead Oral Surgery Kings College London/Hon Consultant Kings College Hospital London, Department Oral Surgery, Bessemer Rd, London, SE1 9RT

*Correspondence to: Karl Bishop

Email:karlbishop@btinternet.com
}

\section{Refereed Paper}

Accepted 19 January 2012

DOI: 10.1038/sj.bdj.2012.418

${ }^{\circ}$ British Dental Journal 2012; 212: 497-498 particularly if they highlight important or significant developments for the dental profession and patient care.

The first of these is an update of the committee's Guidelines for surgical endodontics which were initially produced by Professor William Saunders in 2001. ${ }^{2}$ This update has been produced by Glynis Evans, Karl Bishop and Tara Renton and was agreed by the Clinical Standards Committee of the FDSRCS (Eng) in 2011.

\section{OUTCOME}

The aim of root canal therapy remains the same: to clean, disinfect and seal the root canal system. Where the outcome of initial root canal therapy is uncertain or incomplete then, from an endodontic perspective, consideration can be given to either provide a nonsurgical root canal retreatment or endodontic surgery.

Since 2001 there have been two systematic reviews comparing the outcome of nonsurgical root canal retreatment and surgical endodontics. ${ }^{3,4}$ These highlight that there have been no further randomised controlled trials other than those referred to in the original guidelines. ${ }^{5,6}$ The data from this limited evidence suggests that although surgery may offer a more favourable outcome in the shortterm, nonsurgical retreatment appears to offer a better long-term result. ${ }^{3,4}$ Nonsurgical retreatment may provide a better opportunity to clean the pulp space over a surgical approach and therefore remains the preferred treatment option where appropriate. ${ }^{5}$

This position appears to be supported by the historical data on the outcome of surgical endodontics, which highlights a wide range in success rates (45-97\%). Recently, however, there have been a number of studies evaluating contemporary microsurgical techniques and more biocompatible filling materials. These report more consistent healing outcomes of between $88 \%$ and 96\%. ${ }^{7-9}$ This suggests that modern surgical endodontic techniques, including appropriate case selection, are associated with a high degree of success.

\section{INDICATIONS FOR SURGICAL ENDODONTICS}

There have been no significant changes to the guidelines in relation to the indications for surgical endodontics. These primarily relate to difficultly in access for conventional nonsurgical treatment or retreatment, or where access to the periapical area is necessary to aid diagnosis, for example, for biopsy or to identify a possible root fracture/perforation.

\section{RADIOGRAPHIC ASSESSMENT}

A major development over the past ten years has been the improved access to cone beam computed tomography. The high diagnostic yield of this technique has been described with particular reference to assessment of posterior teeth before periapical surgery. ${ }^{10}$ However, for the majority 
of cases long-cone parallel views of teeth and adjacent structures still remains the most appropriate technique.

\section{CLINCAL MANAGEMENT}

\section{Prophylactic antimicrobials and anti-inflammatories}

The routine use of prophylactic antibiotics to prevent postoperative infection in patients (not otherwise requiring such a regime for medical conditions) has not been shown to be beneficial. ${ }^{11}$ There has been no evidence, however, to negate the consideration of a peri-operative chlorhexidine mouth rinse or non-steroidal antiinflammatory drugs (NSAIDs) to support healing and minimise swelling and postoperative discomfort.

\section{Magnification}

It would appear that most endodontists or those with an interest in the specialty use magnification during endodontic procedures including surgery. Though, the impact of magnification devices on the outcome of endodontic surgery has still not been clearly demonstrated. ${ }^{12}$

However, the use and benefits of the dental operating microscope in terms of improved visualisation and control of the surgical site is well documented. ${ }^{13,14}$ Magnification certainly allows for a more conservative approach which may reduce co-morbidities but in turn makes use of more specialised instrumentation almost essential to achieve the full advantage of a less invasive procedure.

\section{Root-end resection}

Resection of $3 \mathrm{~mm}$ of the root end, as close to 90 degrees to the long axis of the tooth as possible, continues to be the recommendation since this reduces the number of exposed dentinal tubules and facilitates access to all the apical anatomy. ${ }^{15}$

The resected root surface should be examined, preferably under magnification with a micro-mirror, to ensure that the resection is complete, that the surface is smooth, that there are no cracks in the root, and to check for canal irregularities..$^{16,17}$

\section{Root-end preparation}

Again the recommendations remain unchanged since 2001. The preparation should be $3 \mathrm{~mm}$ deep, in the long axis of the tooth and incorporate the whole pulp space morphology. To achieve these objectives root-end preparation is best carried out with an angled, ultrasonically powered tip. ${ }^{18-22}$

The use of these tips minimises the amount of bone that has to be removed to gain access for root end preparation and allows a preparation that more readily follows the long axis of the canal as well as facilitating debridement of isthmuses. The root end cavity should be examined to ensure that the walls are free of debris, including previous root filling materials and this invariably requires the use of magnification techniques.

\section{Root-end filling}

A biologically compatible material should be used where possible and although the guidelines highlight a number of options, mineral trioxide aggregate (MTA) appears to be the material of choice at this time. Amalgam is not recommended. ${ }^{23-26}$

\section{OUTCOMES OF SURGICAL ENDODONTIC INTERVENTION}

The guidelines continue to highlight the importance of regular follow up to assess healing using criteria based upon clinical and radiological examination. Radiological examination should be conducted at annual intervals until healing is observed.

1. Faculty of Dental Surgery of the Royal College of Surgeons of England. Clinical guidelines webpage. http://www.rcseng.ac.uk/fds/publications-clinicalguidelines/clinical_guidelines/index.html (accessed 27 February 2012).

2. Saunders W. Guidelines for surgical endodontics. 2001. Available online at http://www.rcseng.ac.uk/

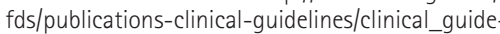
lines/documents/surg_end guideline.pdf (accessed 27 February 2012).

3. Del Fabbro M, Taschieri S, Testori T, Francetti L, Weinstein R. Surgical versus non-surgical endodontic retreatment for periradicular lesions. Cochrane Database Syst Rev 2007; CD005511.

4. Torabinejad M, Corr R, Handysides R, Shabahang S. Outcomes of nonsurgical retreatment and endodontic surgery: a systematic review. J Endod 2009; 35: 930-937.

5. Danin J, Linder $L E_{1}$ Lundqvist $G$, Ohlsson $L$, Ramskold L O, Stromberg T. Outcomes of periradicular surgery in cases with apical pathosis and untreated canals. Oral Surg Oral Med Oral Pathol Oral Radiol Endod 1999; 87: 227-232.

6. Kvist T, Reit $C$. Results of endodontic retreatment: a randomized clinical study comparing surgical and nonsurgical procedures. J Endod 1999; 25: 814-817.

7. Saunders W P. A prospective clinical study of periradicular surgery using mineral trioxide aggregate as a root-end filling. J Endod 2008; 34: 660-665.

8. Tsesis I, Faivishevsky, Kfir A, Rosen E. Outcome of surgical endodontic treatment performed by a modern technique: a meta-analysis of the literature J Endod 2009: 35: 1505-1511.

9. Setzer F C, Shah S B, Kohli M R, Karabucak B, Kim S. Outcome of endodontic surgery: a meta-analysis of the literature - part 1: comparison of traditional root-end surgery and endodontic microsurgery. J Endod 2010; 36: 1757-1765.

10. Patel S, Dawood A, Pitt Ford T, Whaites E. The potential applications of cone beam computed tomography in the management of endodontic problems. Int Endod J 2007; 40: 818-830.

11. Lindenboom J A H, Frenken, J W H, Valkenburg $P$ van den Akker H P. Int Endod J 2005; 38: 877-881.

12. Del Fabbro M, Taschieri S. Endodontic therapy using magnification devices: a systematic review. J Dent 2010; 38: 269-275.

13. Pecora G, Andreana $S$. Use of the dental operating microscope in endodontic surgery. Oral Surg Oral Med Oral Pathol 1993: 75: 751-758.

14. Kim S. Principles of endodontic microsurgery. Dent Clin N Am 1997; 41: 481-497.

15. Gilheany P A, Figdor D, Tyas M J. Apical dentin permeability and microleakage associated with root end resection and retrograde filling. J Endod 1994; 20: $22-26$.

16. Hsu Y Y, Kim S. The resected root surface. The issue of canal isthmuses. Dent Clin North Am 1997; 41: 529-540.

17. Wada M, Takase $T$, Nakanuma $K_{1}$ Arisue $K$ Nagahama F, Yamazaki M. Clinical study of refractory apical periodontitis treated by apicectomy. Part 1. Root canal morphology of resected apex. Int Endod J 1998; 31: 53-56.

18. Gutmann J L, Saunders W P, Nguyen L, Guo I Y, Saunders E M. Ultrasonic root-end preparation. Part 1. SEM analysis. Int Endod J 1994; 27: 318-324.

19. Min M M, Brown C E Jr, Legan J J, Kafrawy A H. In vitro evaluation of effects of ultrasonic root-end preparation on resected root surfaces. J Endod 1997: 23: 624-628.

20. Waplington M, Lumley P J, Walmsley A D. Incidence of root face alteration after ultrasonic retrograde cavity preparation. Oral Surg Oral Med Oral Pathol Oral Radiol Endod 1997: 83: 387-392.

21. Testori T, Capelli M, Milani S, Weinstein R L. Success and failure in periradicular surgery: a longitudinal retrospective analysis. Oral Surg Oral Med Oral Pathol Oral Radiol Endod 1999; 87: 493-498.

22. von Arx T, Walker W A. Microsurgical instruments for root-end cavity preparation following apicoectomy: a literature review. Endod Dent Traumatol 2000; 16: 47-62

23. Allen R K, Newton C W, Brown C E. A statistical analysis of surgical and nonsurgical endodontic retreatment cases. J Endod 1989; 15: 261-266.

24. Dorn S O, Gartner A H. Retrograde filling materials: a retrospective success-failure study of amalgam, EBA and IRM. J Endod 1990; 16: 391-393.

25. Jesslen $P$, Zetterqvist $L$, Heimdahl A. Long-term results of amalgam versus glass ionomer cement as apical sealant after apicectomy. Oral Surg Oral Med Oral Pathol Oral Radiol Endod 1995; 79: 101-103.

26. Pantschev A, Carlsson A P, Andersson L. Retrograde root filling with EBA cement or amalgam. A comparative clinical study. Oral Surg Oral Med Oral Pathol 1994; 78: 101-104. 